\title{
РАЗНООБРАЗИЕ МИКРОСКОПИЧЕСКИХ ГРИБОВ И ИХ РОЛЬ В ВОДНОЙ ЭКОСИСТЕМЕ АЗЕРБАЙДЖАНА
}

\section{DIVERSITY OF MICROSCOPIC FUNGI AND THEIR ROLE IN THE AQUATIC ECOSYSTEM OF AZERBAIJAN}

\section{G. Hasanova}

Summary. The aim of our research is to study microscopic fungi and determine their species composition by the seasons of the year in the rivers of the southern region of Azerbaijan. As a result of studies on the seasons of the year, 33 species belonging to 12 genera were identified. These species were distinguished by different occurrences on the studied rivers and this is associated with the temperature, $\mathrm{pH}$ of the water, dissolved oxygen, with the amount of biogenic element and plant residues.

Keywords: microscopic fungi, aquatic ecosystem, nutrients, river waters, plant residues, Southern region of Azerbaijan.

\section{Введение}

$\Gamma$

рибы являются разнообразной и экологически важной группой эукариотических организмов, встречающихся в каждой экосистеме на Земле [12]. Разнообразие грибов в пресноводных средах обитания велико, и их экологическая роль значительна. Они составляют более 3000 видов, включая аскомицеты, базидиомицеты, хитриды и грибоподобные оомицеты, переносимые водой. Они распространены по всему миру в виде сапробов, и даже они могут быть патогенными для животных, обитающих в водной среде, и для планктона.

Водные гифомицеты впервые были обнаружены в неглубоких, сравнительно среднетекучих холодных водных течениях с хорошей аэрацией [13].

Водные грибы активно участвуют в разложении органических веществ растительных остатков. Их готовят для колонизации различных организмов, в основном бактерий и беспозвоночных организмов [14]. Они являются активными участниками снижения антропогенного стресса, так как в водной среде участвуют в биотрансформации органических ксенобиотиков и поэтому могут улучшить качество воды [16;19]. Участие этой группы организмов в очищении воды и наличие у них характерных свойств в разработке
Гасанова Гульнара Мурсал гызы

H.с., Институт Микробиологии НАНА,

Азербайджанская Республика gulnarahasan.m@gmail.com

Аннотация. Целью нашего исследования является изучение микроскопических грибов и определение их видового состава по сезонам года в воде рек Южного региона Азербайджана. В результате проведенных исследований по сезонам года было определено 33 вида, относящихся к 12 родам. Эти виды отличались разной встречаемостью на исследуемых реках и это связано с температурой, рН воды, растворенным кислородом, с количеством биогенных элементов и растительных остатков.

Ключевые слова: микроскопические грибы, водная экосистема, биогенные элементы, воды рек, растительные остатки, Южный регион Азербайджана.

биотехнологий раньше не принимали во внимание [10]. Связанные с наличием в водной среде остатков растений грибы приспособились к жизни в этой среде. Сравнительно малоизученные грибы рода Ascomycota и Basidiomycota, находящиеся в стадии анаморф, относятся к этим грибам. Они играют важную роль в фундаментальных процессах формирования экосистемы $[18 ; 23]$.

Изучение разнообразия, адаптации и функций грибов в пресноводных экосистемах, на которые воздействует человек, служит исходной информацией и полезно для понимания степени изменения естественной среды обитания с целью разработки мер по сохранению или смягчению стратегий очистки от загрязнения водных экосистем [9].

Грибы являются важными партнерами первичных производителей и основных разлагающих растительной биомассы. Они способствуют почвенным, водным и атмосферным биогеохимическим циклам [20].

Исследования грибов приобрели первостепенное значение благодаря их разнообразной роли в функционировании экосистемы. Несмотря на имеющуюся многочисленную литературу о разнообразии водных гифомицетов, дрожжеподобных и зооспоровых грибов в водных экосистемах, в особенности в речных экоси- 


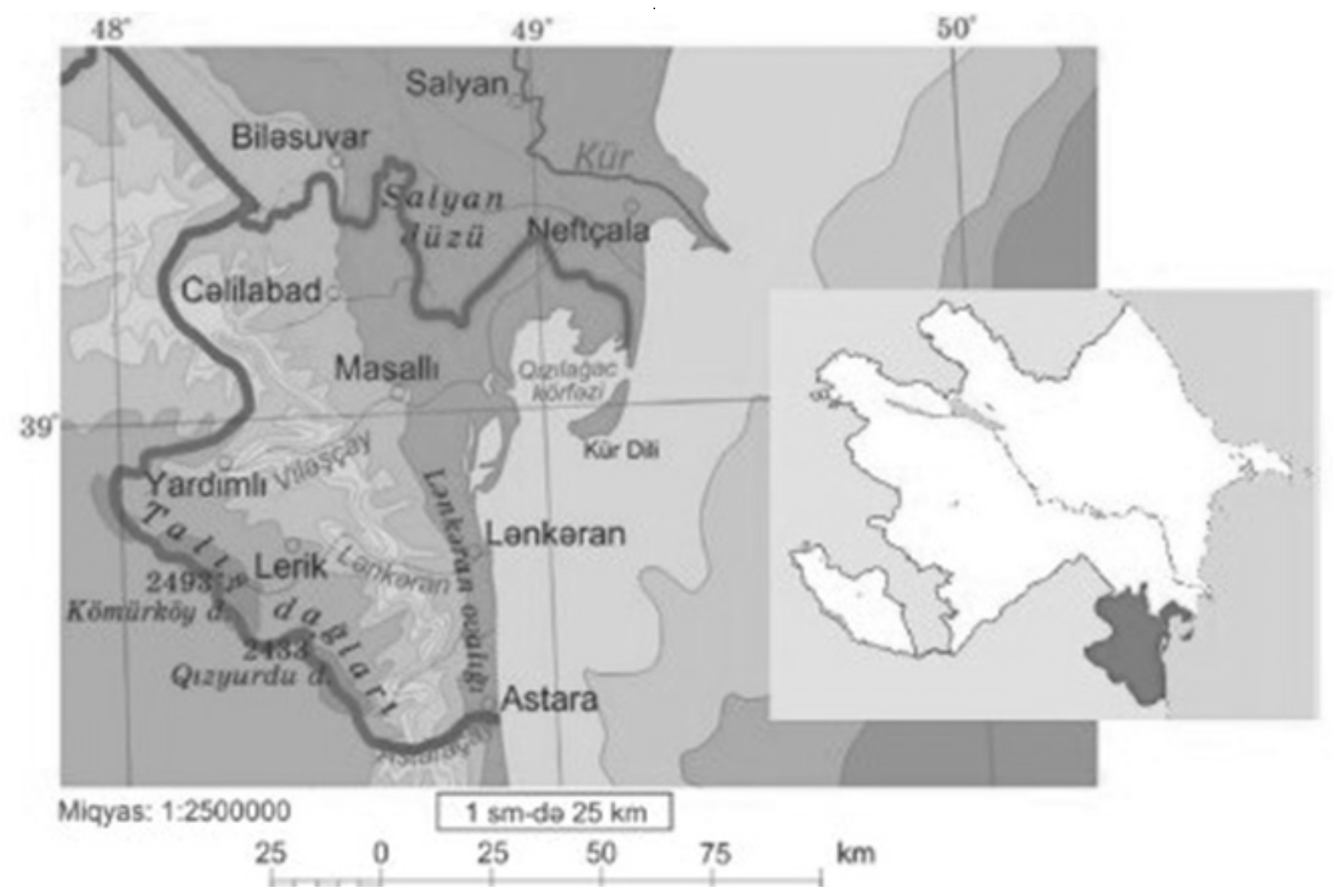

Рис. 1. Карта исследуемых рек Ленкоранской природной области

стемах, [11;15] сведений о количественном составе грибов достаточно мало.

Оценка разнообразия в окружающей среде является важной задачей для мониторинга рисков загрязнения и его возможного контроля. При изучении водных микромицетов основным фактором является распространение и их разнообразие в изучаемых реках.

Целью нашего исследования является изучение микроскопических грибов и определение их видового состава по сезонам года в воде рек Южного региона Азербайджана.

\section{Материал и методы исслеАОвания}

Исследованные реки располагаются в Ленкоранской природный области Азербайджанский Республики. Область находится на $38^{0} 22^{1}-39^{0} 22^{1}$ с. ш и $47^{0} 58^{1}-48^{0} 52^{1}$ в.д. Площадь составляет 6,07 тысяч км². Длина Ленкоранской природной области с севера на юг равна 125 км, а с востока на запад составляет 96 км. В природной области по Талышскому горному хребту и по всей дли- не реки Астарачай в северо-западе и по югу проходит граница с Иранской Исламской Республикой. На территории области 55\% составляет горная часть, а $45 \%$ низменная часть. В области имеются малые и большие реки в количестве 2056, относящиеся к Каспийскому морскому бассейну. Длина всех рек на этой территории составляет 4418 км, общая площадь речных бассейнов равна 5441 км². Исследуемые реки в Ленкоранской области, следующие: Астарачай, Ленкораньчай, Веравулчай, Боладычай, Болгарчай и Виляшчай. Реки Астарачай и Болгарчай являются транзитными [Рис1].

Образцы пробы были взяты по четырем сезонам года из выбранных рек. На исследуемых станциях проводили изучение физико-химических параметров воды: температуру $\left({ }^{0} \mathrm{C}\right), \mathrm{pH}$, растворенный в воде кислород (мг/л), количество биогенных элементов(мг/л) по методам АРНА (Американская ассоциация общественного здравоохранения). Температуру воды измеряли ртутным термометром на глубине 5-7 см воды в течение 5 минут с момента взятия водной пробы, с помощью $\mathrm{pH}$ метра (HM digital pH-200) получали данные водородного показателя. Растворенный в воде кислород измеряли аппаратом ( $M W$-600 dissolved 
Таблица 1. Данные об изменениях абиотических факторов во время сбора проб воды по сезонам года (максимально, минимально)

\begin{tabular}{|l|l|l|l|l|}
\hline Параметр: & 3има & Весна & Лето & Осень \\
\hline Температура $\left({ }^{\circ} \mathrm{C}\right)$ & $6-8$ & $15-20$ & $22-24,5$ & $18-20$ \\
\hline $\mathrm{pH}$ & $7,1-7,6$ & $8,0-8,1$ & $8,0-8,3$ & $8,1-8,2$ \\
\hline Растворенный кислород $\left(\mathrm{mg} \mathrm{O}_{2} / \mathrm{L}^{-1}\right)$ & $10,1-11,9$ & $9,5-10,7$ & $6,2-8$ & $6,5-7$ \\
\hline Биологическое потребление кислорода БПК ${ }^{- \text {-сутки }}$ & 0,55 & 1,3 & 2,6 & 2,2 \\
\hline
\end{tabular}

Таблица 2. Количество биогенных элементов (мг/л) в пробах воды исследуемых рек

\begin{tabular}{|c|c|c|c|c|c|c|c|c|c|c|c|c|c|c|c|c|}
\hline \multirow[b]{2}{*}{ Река } & \multicolumn{4}{|c|}{ Весна } & \multicolumn{4}{|l|}{ Лето } & \multicolumn{4}{|c|}{ Осень } & \multicolumn{4}{|c|}{ Зима } \\
\hline & $\begin{array}{l}\frac{5}{5} \\
\frac{\mathbf{L}}{2}\end{array}$ & $\begin{array}{l}\frac{5}{\mathbf{L}} \\
\varrho^{m}\end{array}$ & $\frac{5}{\sum^{5}}$ & $\begin{array}{l}\frac{5}{5} \\
\frac{1}{2} \\
8\end{array}$ & $\frac{5}{\sum_{0}^{2}}$ & $\begin{array}{l}\frac{5}{L} \\
\frac{2}{2} \\
\frac{0}{2}\end{array}$ & $\frac{5}{\frac{5}{5}}$ & $\frac{5}{\frac{5}{5}}$ & $\frac{5}{\sum}$ & $\begin{array}{l}\frac{5}{L} \\
\frac{1}{2} \\
\frac{\infty}{Z}\end{array}$ & $\frac{5}{\frac{5}{2}}$ & $\begin{array}{l}\frac{5}{5} \\
\frac{1}{2} \\
8 \\
8\end{array}$ & $\frac{5}{\sum_{0}^{\prime}}$ & $\begin{array}{l}\frac{5}{L} \\
\frac{2}{2} \\
\frac{0}{Z}\end{array}$ & $\frac{\frac{5}{L}}{\frac{5}{z}}$ & $\begin{array}{l}5 \\
\frac{5}{2} \\
0\end{array}$ \\
\hline Астарачай & 0,01 & 0,56 & 0,05 & 0,01 & 0,00 & 0,48 & 1,20 & 0,00 & 0,02 & 0,70 & 1,50 & 0,01 & 0,02 & 0,70 & 1,50 & 0,01 \\
\hline Ленкораньчай & 0,02 & 0,76 & 0,04 & 0,06 & 0,00 & 0,65 & 0,08 & 0,02 & 0,03 & 0,85 & 0,10 & 0,04 & 0,03 & 0,85 & 0,10 & 0,04 \\
\hline Веравулчай & 0,00 & 0,40 & 0,03 & 0,01 & 0,00 & 0,32 & 0,06 & 0,00 & 0,01 & 0,60 & 0,10 & 0,01 & 0,01 & 0,60 & 0,10 & 0,01 \\
\hline Боладычай & 0,02 & 0,40 & 0,07 & 0,02 & 0,00 & 0,38 & 0,12 & 0,00 & 0,04 & 0,50 & 0,18 & 0,01 & 0,04 & 0,50 & 0,18 & 0,01 \\
\hline Виляшчай & 0,03 & 0,36 & 0,15 & 0,01 & 0,01 & 0,30 & 0,25 & 0,01 & 0,06 & 0,45 & 0,40 & 0,03 & 0,06 & 0,45 & 0,40 & 0,03 \\
\hline Болгарчай & 0,02 & 0,38 & 0,03 & 0,02 & 0,00 & 0,36 & 0,20 & 0,00 & 0,04 & 0,48 & 0,20 & 0,01 & 0,04 & 0,55 & 0,20 & 0,01 \\
\hline
\end{tabular}

Oxygen), а количество биогенных элементов-с помощью аппарата Palintest photometr7100). При отборе проб воды в работе нами были использованы общепринятый методы в микологических исследованиях [6;7;8]. Пробы водыбыли взяты в стерильные пластиковые контейнеры, а остатки растений были собраныв стерильные пластиковые пакеты.Посевы проб-образцов проводились на стандартных питательных агаровых средах Чапека и картофельно-декстрозном агаре (CDA и PDA) в чашках Петри. Посевы были инкубированы в термостате при температуре $28 \pm 2^{0} \mathrm{C}$.Через 3 дня после инокуляции выросшие мицелии проверяли под микроскопом, а затем каждый кончик гиф переносили на новую чашку со средой Чапек. После 7-ми дней инкубации измеряли диаметр колоний и отмечали их свойства. В конце исследований с помощью микроскопа Olympus CX 41 были определены виды грибов и отмечена быстрота встречаемости выделенных микромицетов [5;17;21;22].

\section{Полученные результаты и их обсужАение}

Для оценки действия окружающей среды и климатических условий на разнообразие грибов в воде были проведены ряд экологических исследований и было установлено, что в воде исследуемых рек разнообразие грибов зависит от многих абиотических, климатических и эдафических факторов. В естественных условиях грибы редко сталкиваются с условиями, обеспечивающими оптимальный рост, поскольку они обусловлены абиотическими факторами, доступностью питательных веществ и загрязнителями.

Абиотические факторы считаются наиболее важными для водных микромицетов, поэтому, в период проведенных исследований температура воды показывала выраженные сезонные изменения (табл. 1). Температура воды рек менялась в пределах 6-24,5 градусах, и в связи с этим была определена зависимость видов микроскопических грибов от изменений температуры, потому что эти изменения меняют видовую плотность конидиальных грибов. Отмечено, что количество видов уменьшается с понижением температуры воды. Как видно из таблицы, водородный показатель рН меняется в пределах 7,1-8,3 и имеет тесную связь с распространением водных конидиальных грибов.

Количество растворенного в воде кислорода менялось в пределах 6,2-11,9 мг/л. Растворимый в воде 
Таблица 3. Систематический состав микроскопических грибов, выделенных из воды исследуемых рек

\begin{tabular}{|c|c|c|c|c|}
\hline Класс & Порядок & Семейство & Род & $\begin{array}{l}\text { Количество } \\
\text { видов }\end{array}$ \\
\hline \multirow{2}{*}{ Mucoromycotina } & \multirow{2}{*}{ Mucorales } & \multirow{2}{*}{ Mucoraceae } & Mucor & 4 \\
\hline & & & Rhizopus & 1 \\
\hline \multirow{2}{*}{ Eurotiomcetes } & \multirow{2}{*}{ Eurotiales } & \multirow{2}{*}{ Trichocomaceae } & Aspergillus & 9 \\
\hline & & & Penicillium & 7 \\
\hline \multirow{4}{*}{ Sordariomycetes } & \multirow{3}{*}{ Hypocreales } & Nectriaceae & Fusarium & 3 \\
\hline & & \multirow{2}{*}{ Hypocreaceae } & Trichoderma & 2 \\
\hline & & & Acremonium & 1 \\
\hline & Sphaeriales & Chaetomiaceae & Chaetomium & 1 \\
\hline \multirow{2}{*}{ Dothideomycetes } & Capnodiales & Davidiellaceae & Cladosporium & 2 \\
\hline & Pleosporales & Pleosporaceae & Alternaria & 1 \\
\hline Sordariomycetes & Microascales & Microscaceae & Scopulariopsis & 1 \\
\hline Saccharomycetes & Saccharo-mycetales & Saccharo-mycetaceae & Candida & 1 \\
\hline
\end{tabular}

кислород (табл. 1) максимально наблюдается зимнюю, а минимально-в летний сезон.

Как видно из таблицы 1, в исследуемых речных водах в зависимости от сезона года температура воды варьировала от $6^{\circ} \mathrm{C}$ до $24,5^{\circ} \mathrm{C}$, показатели водородного индекса составляли $\mathrm{pH} 7,1-8,3$. Количество растворенного в воде кислорода было в пределах 6,2-11,9 мг/л, биологическое потребление кислорода менялось от 0,55 до 2,6 мг/л.

Эти факторы считаются наиболее важными для водных гифомицетов, поскольку хорошо аэрированные воды могут способствовать росту и споруляции этой группы грибов [4; 17].

Как отмечено, биогенные элементы играют важную роль в развитии грибов. В связи с этим в пробах воды определяли наличие ионов-нитритов, нитратов, аммония и фосфора (таблица 2).

Увеличение количества ионов нитритов и аммония в водных бассейнах связано с попаданием в них большого количества растительных остатков и их разложением. Причиной повышения количества нитратов в поверхностных водах весной и осенью являются весенние и осенние дожди и наличие земного покрова, являющегося основным источником нитратов. Изменение количества фосфора связано с процессами, происходящими как в водных бассейнах, так и в окружающей среде. Частота встречаемости грибов меняется в зависимости от количества в воде биогенных элементов.
Грибы, выделенные из воды исследуемых рек, показаны в таблице 3.

Как видно из таблицы, идентифицированные микроскопические грибы включают 6 классов, 8 порядков, 9 семейств и 12 родов.

Выделенные и идентифицированные микромицеты по сезонам года показаны в таблицах 4 и 5.

Как видно из этих таблиц, грибы чаще всего встречаются в летний и осенний сезоны года. В исследуемых водах мы чаще всего встречали роды грибов Aspergillus, Penicillium, Fusarium, Trichoderma, Cladosporium и Mucor.

Как видно из таблиц 4 и 5грибы, относящиеся к родам Aspergillus и Penicillium в водной экосистеме Ленкоранской природной области доминируют в формировании микробиоты [1;2;3].

\section{Зак^ючение}

Во время исследований рек были отобраны 80 проб воды и растительных остатков. Из них были выделены и идентифицированы 33 вида микромицетов, относящихся к 12 родам, 9 семейств, 8 порядков и 6 классов. Наряду с этим была определена частота встречаемости грибов по выбранным рекам и выяснено, что в водной экосистеме чаще всего встречаются роды грибов Aspergillus, Penicillium, Mucor, Fusarium, Trichoderma и Cladosporium. В проведенных исследованиях по се- 
Таблица 4. Виды микроскопических грибов, выделенных из воды рек Астарачай, Ленкораньчай, Веравулчай, по сезонам года

\begin{tabular}{|c|c|c|c|c|c|c|c|c|c|c|c|c|}
\hline \multirow[b]{2}{*}{ Вид } & \multicolumn{3}{|c|}{ Весна } & \multicolumn{3}{|l|}{ Лето } & \multicolumn{3}{|c|}{ Осень } & \multicolumn{3}{|c|}{ Зима } \\
\hline & 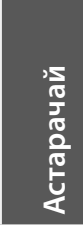 & 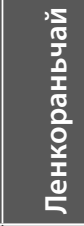 & 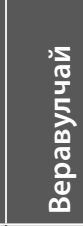 & 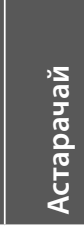 & 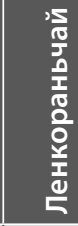 & 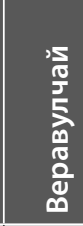 & 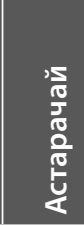 & 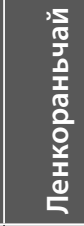 & 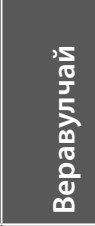 & 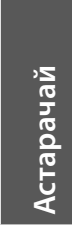 & 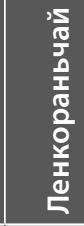 & 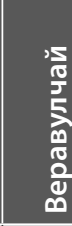 \\
\hline Aspergillusniger & $x$ & $x$ & - & $x$ & $x$ & $x$ & $x$ & $x$ & $x$ & - & $x$ & - \\
\hline A.flavus & - & - & $x$ & - & $x$ & $x$ & $x$ & $x$ & $x$ & - & - & $x$ \\
\hline A.nidulans & - & - & - & - & $x$ & - & $x$ & $x$ & - & - & - & - \\
\hline A.versicolor & - & $x$ & - & - & - & $x$ & - & $x$ & - & - & - & $x$ \\
\hline A.fumigatus & $x$ & - & $x$ & - & $x$ & $x$ & $x$ & - & $x$ & $x$ & - & - \\
\hline A.candidus & - & - & - & - & $x$ & - & $x$ & $x$ & $x$ & - & - & - \\
\hline A.terreus & $x$ & - & $x$ & $x$ & $x$ & $x$ & - & - & $x$ & - & - & - \\
\hline A.carneus & - & - & - & - & - & $x$ & $x$ & $x$ & $x$ & - & - & - \\
\hline A.ochraceus & $x$ & $x$ & - & - & $x$ & $x$ & - & $x$ & $x$ & - & $x$ & - \\
\hline Penicilliumochrochloron & - & - & - & $x$ & - & $x$ & $x$ & - & $x$ & - & - & - \\
\hline P.cyclopium & - & - & $x$ & & - & $x$ & $x$ & $x$ & $x$ & - & - & - \\
\hline P.notatun & - & - & - & $x$ & $x$ & - & $x$ & $x$ & $x$ & - & - & $x$ \\
\hline P.brevicompactum & - & - & - & - & $x$ & - & $x$ & $x$ & - & - & - & - \\
\hline P.funiculosum & - & - & - & - & - & $x$ & - & - & $x$ & - & - & - \\
\hline P.arenarium & - & - & - & - & - & - & $x$ & - & - & - & - & - \\
\hline P.frequentans & - & - & - & - & - & - & $x$ & - & $x$ & - & - & - \\
\hline Fusariumoxysporum & - & $x$ & - & - & $x$ & $x$ & $x$ & $x$ & - & - & $x$ & - \\
\hline F.solani & - & - & - & - & $x$ & $x$ & $x$ & $x$ & $x$ & - & - & $x$ \\
\hline F.culmorum & - & $x$ & - & $x$ & $x$ & $x$ & $x$ & $x$ & $x$ & - & - & \\
\hline Trichodermaviride & $x$ & - & - & $x$ & $x$ & - & $x$ & $x$ & $x$ & - & - & $x$ \\
\hline T.harzianum & - & $x$ & - & $x$ & $x$ & - & $x$ & $x$ & - & - & - & - \\
\hline Alternariaalternaria & - & - & - & $x$ & $x$ & $x$ & - & $x$ & $x$ & - & $x$ & - \\
\hline Acremoniumrutilum & - & - & - & - & $x$ & - & $x$ & $x$ & $x$ & - & - & - \\
\hline Cladosporiumherbarum & $x$ & - & - & $x$ & $x$ & $x$ & $x$ & $x$ & $x$ & - & - & - \\
\hline C.cladosporioides & - & - & - & - & - & - & - & $x$ & $x$ & - & - & - \\
\hline Candida albicans & $x$ & - & - & - & $x$ & $x$ & - & - & $x$ & - & - & - \\
\hline Chaetomium globosum & - & - & $x$ & $x$ & $x$ & - & $x$ & $x$ & $x$ & - & $x$ & \\
\hline Scopulariopsis. sp & $x$ & - & - & - & $x$ & - & $x$ & $x$ & - & - & - & - \\
\hline Mucorracemosus & - & - & - & - & - & $x$ & - & - & $x$ & - & - & - \\
\hline M. mucedo & - & - & - & - & $x$ & - & - & $x$ & - & - & - & - \\
\hline M.hiemalis & - & - & - & - & - & $x$ & - & - & $x$ & - & - & - \\
\hline M. corymbifer & $x$ & - & - & - & $x$ & - & - & $x$ & $x$ & - & - & - \\
\hline Rhizopus.sp & - & - & - & - & $x$ & - & $x$ & $x$ & $x$ & $x$ & - & - \\
\hline
\end{tabular}


Таблица 5. Виды микроскопических грибов, выделенных из воды рек Боладычай, Виляшчай, Болгарчай, по сезонам года

\begin{tabular}{|c|c|c|c|c|c|c|c|c|c|c|c|c|}
\hline \multirow[b]{2}{*}{ Вид } & \multicolumn{3}{|c|}{ Весна } & \multicolumn{3}{|c|}{ Лето } & \multicolumn{3}{|c|}{ Осень } & \multicolumn{3}{|c|}{ Зима } \\
\hline & 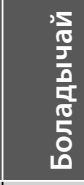 & 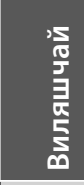 & 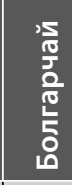 & 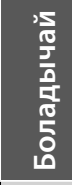 & 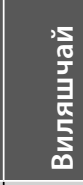 & $\begin{array}{l}\text { 도 } \\
\text { 움 } \\
\text { 을 } \\
\frac{5}{5} \\
10\end{array}$ & 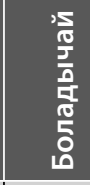 & 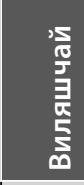 & 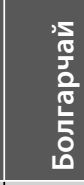 & $\begin{array}{l}\text { 도 } \\
\frac{10}{5} \\
\frac{0}{0} \\
\frac{1}{10} \\
5 \\
0\end{array}$ & 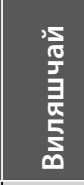 & 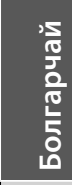 \\
\hline Aspergillusniger & - & $x$ & - & $x$ & $x$ & $x$ & $x$ & $x$ & $x$ & $x$ & - & - \\
\hline A.flavus & - & $x$ & - & - & $x$ & - & $x$ & $x$ & - & - & - & - \\
\hline A.nidulans & - & - & - & - & $x$ & $x$ & - & $x$ & - & - & - & - \\
\hline A.versicolor & - & $x$ & - & - & - & $x$ & $x$ & $x$ & - & - & $x$ & $x$ \\
\hline A.fumigatus & $x$ & - & - & - & $x$ & - & - & $x$ & $x$ & $x$ & - & - \\
\hline A.candidus & - & - & - & $x$ & - & - & $x$ & $x$ & - & - & - & - \\
\hline A.terreus & $x$ & - & $x$ & - & $x$ & $x$ & $x$ & - & $x$ & - & - & - \\
\hline A.carneus & - & - & - & - & $x$ & - & $x$ & - & $x$ & - & - & - \\
\hline A.ochraceus & - & $x$ & - & $x$ & $x$ & $x$ & $x$ & $x$ & - & - & - & - \\
\hline Penicilliumochrochloron & - & - & - & $x$ & $x$ & $x$ & $x$ & - & $x$ & - & $x$ & - \\
\hline P.cyclopium & $x$ & - & - & - & - & - & - & $x$ & $x$ & - & - & - \\
\hline P.notatun & $x$ & - & - & $x$ & $x$ & - & $x$ & - & $x$ & - & - & - \\
\hline P.brevicompactum & - & $x$ & - & - & - & $x$ & - & $x$ & - & - & - & - \\
\hline P.funiculosum & - & - & - & - & - & $x$ & $x$ & $x$ & - & - & - & - \\
\hline P.arenarium & - & - & - & - & - & - & - & $x$ & - & - & - & - \\
\hline P.frequentans & - & - & - & - & - & - & $x$ & $x$ & - & - & - & - \\
\hline Fusariumoxysporum & - & - & $x$ & - & $x$ & - & $x$ & $x$ & $x$ & - & - & - \\
\hline F.solani & - & - & - & $x$ & - & $x$ & $x$ & - & $x$ & $x$ & - & - \\
\hline F.culmorum & - & - & - & $x$ & - & - & $x$ & - & - & - & - & - \\
\hline Trichodermaviride & $x$ & - & $x$ & - & $x$ & $x$ & $x$ & $x$ & $x$ & - & $x$ & - \\
\hline T.harzianum & - & $x$ & - & $x$ & $x$ & - & $x$ & $x$ & - & $x$ & - & - \\
\hline Alternariaalternaria & - & - & $x$ & - & $x$ & $x$ & $x$ & $x$ & $x$ & $x$ & - & - \\
\hline Acremoniumrutilum & - & - & - & $x$ & - & $x$ & - & $x$ & $x$ & - & - & - \\
\hline Cladosporiumherbarum & - & $x$ & - & $x$ & $x$ & $x$ & $x$ & $x$ & $x$ & $x$ & - & - \\
\hline C.cladosporioides & - & - & - & - & - & - & - & $x$ & - & - & - & - \\
\hline Candida albicans & - & - & - & - & $x$ & $x$ & - & $x$ & - & - & - & - \\
\hline Chaetomium globosum & - & - & - & - & $x$ & - & - & - & $x$ & - & - & - \\
\hline Scopulariopsis. sp & $x$ & - & - & - & $x$ & $x$ & - & $x$ & - & $x$ & - & - \\
\hline Mucorracemosus & - & - & - & - & - & $x$ & $x$ & - & - & - & - & - \\
\hline M. mucedo & - & - & - & $x$ & - & - & - & - & - & - & - & - \\
\hline M.hiemalis & - & - & - & - & $x$ & - & $x$ & - & - & - & - & - \\
\hline M. corymbifer & - & - & - & - & - & - & - & $x$ & - & - & - & - \\
\hline Rhizopus.sp & - & $x$ & - & - & $x$ & - & $x$ & $x$ & - & $x$ & - & - \\
\hline
\end{tabular}

Примечание: (x) - встречаемые виды, (-) - не встречаемые виды 
зонам года было определено, что грибы различаются по частоте встречаемости, особенно в конце лета и осенью они встречаются чаще. И это связано с повышением температуры воды и увеличением в ней количества органических веществ. В результате исследований мы определили, что во время листопада происходит обогащение водных экосистем остатками растений, и вследствие этого идет увеличение разнообразия водных микромицетов. Это связано не только с увеличением температуры, рН среды, растворенным кислородом, с количеством биогенных элементов, но и насыщением воды питательными веществами растительных остатков. Установлено, что количество обнаруженных микромицетов в пробах воды, взятых из глубины относительно низкое, чем в пробах воды, взятых с поверхности.

\section{Б^агоАарность}

Выражаем глубокую благодарность профессору Ахмад Асану и доценту Бурхану Шену из университета Тракья. г. Эдирне (Турция) за оказание помощи в идентификации грибов.

\section{ЛИТЕРАТУРА}

1. Гасанова Г.М., Бабашлы А.А. Микологическая характеристика речных вод Южного региона Азербайджанской республики //Вестник Московского государственного областного университета. Серия: Естественные науки, — 2017, № 3, -с.6-14

2. Гасанова Г.М. Разнообразие микромицетов в водах рек южного региона Азербайджана / Первая международная конференция молодых ученых, Гянджа- 2016, -с.264-266.

3. Гасанова Г.М. Микробиота речных вод южного региона Азербайджанской республики //Труды Института Микробиологии НАНА, 2016, т. 14, № 1, c. $260-263$.

4. Дудка И.А., Вассер С.П., Элланская И.А. Методы экспериментальной микологии. -Киев: «Наукова думка»,_1982,_-550с.

5. Дудка И.А. Водные несовершенные грибы. К: Наук. Думка, - 1985, - 188с.

6. Литвинов М.А., Дудка И.А. Методы исследования икроскопических грибов пресных и соленых (морских) водоемов. -Л.: Наука, 一 $1975,-152$ с.

7. Романенко В.И., Кузнецов С.И. Экология микроорганизмов пресных водоемов. Лабораторное руководство. -Л. «Наука», — 1974, 一 194с.

8. Родина А.Г. Методы водной микробиологии. -М-П: «Наук»,-1965,- 354 с.

9. Салманов М.А., Манафова А.А., Ансарова А.Г., Гусейнов А.Т. Микромицеты-мигранты Мингячевирского водохранилища // Юг России: экология, развитие.-2017, т. 12, № 1, -с.54-61. https://doi.org/10.18470/1992-1098-2017-1-54-61

10. Anna P., Andrzej S.G., Adam W., Adam C. Biomass and Abundance of Aquatic Fungi in a Polyhumic Dam Reservoir // Pol. J. Environ. Stud., 一 2013, vol. 22, № 3, p.819-824.

11. Christian M.W., Felix Bärlocher., Hans P.G. Fungi in lake ecosystems //AME, —2010, vol. 59, -p.125-149. D0I: https://doi.org/10.3354/ame01385

12. Huzefa A.R., Carol A.S., Clement K-M.T. Fershwater fungi //eLS Microbiology,-2018, -p.1-13.

13. Ingold C.T. Aquatic hyphomycetes of decaying alder leaves //Transactions of the British Mycological Society, - 1942, vol. 34, -p.210-215.

14. 14.Krauss G.J., Solé M., Krauss G., Schlosser D., Wesenberg D., Bärlocher F. Fungi in freshwaters: ecology, physiology and biochemical potetntial //FEMS Microbiol. Rev, -2011, vol.35, № 4, -p.620-651. D0l: 10.1111/j.1574-6976.2011.00266.x.

15. Kabir G.P., Peter G.K., and Thomas D.B. Fungal Community Ecology: A Hybrid Beast with a Molecular Master//Bio Science,—2008, vol. 58, № 9, -p.799-810 https://doi.org/10.1641/B580907

16. Miersch J., Grancharov K. Cadmium and heat response of the fungus Heliscuslugdunensis isolated from highly polluted and unpolluted areas//Amino Acids, - 2008, vol.34, № 2, -p.271-277. D01:10.1007/s00726-006-0491-y

17. Nilsson S.C. Freshwater hyphomycetes. Taxonomy morphology and ecology //Symbolae Botanica Upsalienses,—1964, vol.18, № 2, -p.1-130.

18. Patrícia 0.F., Taimy Cantillo-Pérez., Vladislav G\&Luís F.P.G. Ingoldian fungi of Brazil: some new records and a review including a checklist and a key // Phytotaxa, -2017, vol.306, № 3, -p.171-200. D0l: https://doi.org/10.11646/phytotaxa.306.3.1

19. Qi B., Moe W \& Kinney K. Biodegradation of volatile organic compounds by five fungal species //Applied Microbiol Biotechnol, — 2002, vol.58, № 5, -p.684-689.

20. Ruben L-M., Vendula B., Martina Š., Anna Davidová., Jan Jansa, Tomaš C \& Petr B. Decomposer food web in a deciduous forest shows high share of generalist microorganisms and importance of microbial biomass recycling // The ISME Journal,_2018, vol.12, -p.1768-1778. D0I: https://doi.org/10.1038/s41396018-0084-2

21. Samson R.A., Visagie C.M., Houbraken J. et al. Phylogeny, identification and nomenclature of the genus Aspergillus // Stud Mycol., - 2014, vol.78, -p.141-173. DOI: 10.1016/j.simyc0.2014.07.004

22. Samson R.A., Houbraken J., Thrane U., Frisvad J.C., Andersen B. Food and Indoor Fungi //CBS laboratory manual series 2, CBS-Fungal Biodiversity Centre, Utrecht, Netherlands, - 2010. - $390 \mathrm{p}$.

23. Shearer C.A., Descals E., Kohlmeyer B., Kohlmeyer J., Marvanová L., Padgett D., Porter D., Raja H.A., Schmit J.P., Thorton H.A. \&Voglymayr H. Fungal biodiversity in aquatic habitats // Biodiversity and Conservation, -2007, vol.16, -p.49-67. D0I: 10.1007/s10531-006-9120-z

( Гасанова Гульнара Мурсал гызы ( gulnarahasan.m@gmail.com ).

Журнал «Современная наука: актуальные проблемы теории и практики» 